\title{
Eficácia de vacinas comerciais contra clostridioses frente ao desafio com Clostridium sordellii
}

\author{
Efficacy of commercial vaccines to clostridiosis challenged with Clostridium sordellii
}

\author{
Francisco Carlos Faria Lobato ${ }^{1}$ Ronnie Antunes de Assis ${ }^{1}$ Gláucia Mansur Balsamão ${ }^{1}$ \\ Vera Lúcia Viegas de Abreu ${ }^{1}$ Ricardo Aurélio Pinto do Nascimento ${ }^{2}$ Ronaldo Dias Neves ${ }^{3}$
}

\section{RESUMO}

\begin{abstract}
Determinou-se a eficácia de doze vacinas contra clostridioses comercializadas no Brasil que contêm em sua composição Clostridium sordellii, pelo método de desafio em cobaias imunizadas. Como referência dos testes, empregouse uma bacterina monovalente padrão. Duas vacinas (16,6\%), codificadas como T6 e T8, apresentaram resultado igual à bacterina padrão, protegendo todos os animais desafiados. Uma vacina (8,3\%), codificada como T10, não atendeu aos requisitos mínimos exigidos no primeiro teste, mas após o reteste foi considerada eficiente. As demais vacinas (75\%), codificadas como T1, T2, T3, T4, T5, T7, T9, T11 e T12, não foram eficientes.
\end{abstract}

Palavras-chave: clostridioses, vacina, Clostridium sordellii.

\section{ABSTRACT}

Twelve commercial vaccines against clostridiosis commercialized in Brazil which have in their composition Clostridium sordellii were evaluated for efficacy. A standard monovalent bacterin was used as a reference test. Two of the tested vaccines (16.6\%), codified as T6 and T8, gave the same results as the standard bacterin, protecting all the challenged animals. One vaccine (8.3\%), codified as T10, after being retested was considered efficient. The remaining vaccines (75\%), codified as T1, T2, T3, T4, T5, T7, T9, T11 and T12, were considered inefficient.

Key words: clostridiosis, vaccine, Clostridium sordellii.

\section{INTRODUÇÃO}

A ocorrência de enfermidades causadas por Clostridium sordellii tem sido relatada em vários países, acometendo principalmente ovinos com quadros de morte súbita (RICHARDS \& HUNT, 1982; LEWIS \& NAYLOR, 1998). C. sordellii tem sido isolado de casos de gangrena gasosa tanto no homem como nos animais (BUXTON \& FRASER, 1977). No Brasil, não há dados oficiais de ocorrência deste agente, pois, apesar do número de focos e de animais afetados por clostridioses ser elevado, a maior parte dos diagnósticos é baseada apenas em dados clínicos e/ou lesões de necropsia.

Nas clostridioses, pelo caráter agudo e dificuldade de tratamentos eficazes, medidas preventivas devem ser adotadas, sendo a utilização de vacinas a principal estratégia a ser empregada. No Brasil, em 2000, foram produzidas 129.969.577 doses de vacinas contra clostridioses, sendo que, aproximadamente, 78 milhões foram de vacinas polivalentes com diferentes associações entre $\boldsymbol{C}$. sordellii, $\boldsymbol{C}$. chauvoei, $\boldsymbol{C}$. septicum, $C$. novyi, $C$. perfringens $\mathrm{B}, \mathrm{C}$ e $\mathrm{D}, \boldsymbol{C}$. tetani e $\boldsymbol{C}$. botulinum C e D (R. D. Neves, comunicação pessoal, LARA/RS, 2001). Entretanto, apenas C. chauvoei e toxóide botulínico são submetidos a controle oficial.

Este trabalho teve por objetivo avaliar a eficácia de vacinas polivalentes contra clostridioses comercializadas no Brasil que contêm em sua composição $\boldsymbol{C}$. sordellii.

\section{MATERIAL E MÉTODOS}

Foram testadas 12 vacinas polivalentes comercializadas no Brasil contendo em sua composição

\footnotetext{
${ }^{1}$ Médico Veterinário, Universidade Federal de Minas Gerais, Escola de Veterinária, Departamento de Medicina Veterinária Preventiva, Av. Antônio Carlos 6627, CP 567, 30123-970, Belo Horizonte, MG, Brasil. E-mail: flobato@vet.ufmg.br Autor para correspondência.

${ }^{2}$ Médico Veterinário, Ministério da Agricultura, Pecuária e Abastecimento, Pedro Leopoldo, MG, Brasil (LARA-MG)

${ }^{3}$ Médico Veterinário, Ministério da Agricultura, Pecuária e Abastecimento, Porto Alegre, RS, Brasil (LARA-RS)
} 
C. sordellii, codificadas de $\mathrm{T}_{1}$ a $\mathrm{T}_{12}$ e como referência utilizou-se uma bacterina monovalente padrão (IPR 308) adquirida do United States Department of Agriculture (USDA), Animal and Plant Health Inspection Service.

Para obtenção da suspensão de esporos utilizada nos testes, foi utilizada uma amostra de $\boldsymbol{C}$. sordellii (ATCC-9714) proveniente da American Type Culture Colletion (Rockville, Maryland, USA). A amostra teve sua identidade confirmada pela técnica de imunofluorescência direta, usando conjugado antiC. sordellii conforme ASSIS et al. (2001). Na produção de esporos, foi empregada a técnica descrita por KOLBE et al. (1981). Previamente à titulação da suspensão de esporos, avaliou-se a pureza da mesma por meio de cultivo em caldo Tioglicolato (Dignolab, Barcelona, Espanha), em atmosferas de anaerobiose e aerobiose, a $37^{\circ} \mathrm{C}$, e posterior coloração de Gram. A titulação da suspensão glicerinada de esporos foi realizada utilizando-se diluições decimais em solução salina estéril tamponada a 1\%, pH 7,0. A dose letal a $50 \%$ - DL D $_{50}$ menor quantidade de esporos capaz de matar 50\% dos animais inoculados em até 72 horas após a inoculação) foi calculada pelo método de REED \& MUENCH (1938). Para cada diluição, foram inoculadas cinco cobaias, cada uma com $0,5 \mathrm{~mL}(0,25 \mathrm{~mL}$ de cada diluição e $0,25 \mathrm{~mL}$ de cloreto de cálcio $\left(\mathrm{CaCl}_{2}\right)$ a 5\%), por via intramuscular. Os animais foram observados por 72 horas. Cada titulação foi repetida três vezes e os resultados dos três testes foram acumulados para efeito de cálculo da $\mathrm{DL}_{50}$. As suspensões de esporos foram mantidas a $-70^{\circ} \mathrm{C}$ e retestadas após 12 meses.

A técnica utilizada para avaliação das vacinas foi a recomendada pelo Code of Federal Regulations-CFR (EUA, 1991). A avaliação da potência dos imunógenos foi feita pela imunização de oito cobaias para cada vacina com $1 / 5$ da dose bovina por via subcutânea. Vinte e um dias após a primovacinação foi dada uma dose de reforço. Aos 14 dias após a segunda dose, todos os animais vacinados e um grupo de cinco animais controle (testemunhas) receberam, por via intramuscular, $0,5 \mathrm{~mL}$ de uma suspensão de esporos de $\boldsymbol{C}$. sordellii contendo 100 $\mathrm{DL}_{50} \mathrm{em} \mathrm{CaCl}_{2}$ a 2,5\%. As cobaias inoculadas foram observadas por 72 horas, registrando-se as mortes ocorridas no período. A prova foi considerada válida quando no mínimo quatro das cinco testemunhas não sobreviveram. Para ser considerada eficaz a vacina deveria satisfazer a um dos seguintes critérios (EUA, 1991): proteger no mínimo sete de oito animais vacinados em um desafio ou proteger no mínimo doze de dezesseis animais vacinados em dois desafios, caso apenas seis animais sobrevivam ao primeiro desafio.

\section{RESULTADOS E DISCUSSÃO}

No teste de pureza da suspensão de esporos, ocorreu crescimento somente em condições de anaerobiose. A partir de esfregaços deste cultivo corados pelo Gram, foram visualizados apenas bastonetes Gram-positivos, esporulados em sua maioria.

A produção de esporos no meio descrito por KOLBE et al. (1981) apresentou resultado satisfatório, confirmado por técnica de coloração (BIER, 1985), com presença maciça de esporos subterminais. O grande crescimento na superfície do meio, provavelmente, foi favorecido pelo fato de o mesmo ter sido preparado em frascos tipo erlenmeyer de gargalo com diâmetro estreito, que após o ciclo de esterilização com descompressão rápida, foi imediatamente acondicionado em jarras de anaerobiose com mistura gasosa até o momento da inoculação.

A média do título da suspensão de esporos para a primeira titulação foi $1,14 \times 10^{5} \mathrm{DL}_{50} \mathrm{~mL}^{-1}$, apresentando desvio padrão de 0,075 e um coeficiente de variação da amostra de $1,4 \%$. A suspensão de esporos glicerinada mantida a $-70^{\circ} \mathrm{C}$ mostrou-se estável por um período de 12 meses, apresentando títulos semelhantes aos obtidos previamente (Tabela 1). Os resultados da potência dos imunógenos comerciais e da bacterina referência são apresentados na tabela 2 .

Dos imunógenos comerciais avaliados, apenas três vacinas atenderam aos requisitos para aprovação no teste de potência. As vacinas $T_{6}$ e $T_{8}$ apresentaram resultados iguais à bacterina monovalente de referência, protegendo todos os animais desafiados. A vacina $T_{10}$ não atendeu aos requisitos para ser considerada eficaz no primeiro teste, entretanto, ao ser retestada, o acumulado de óbitos não foi maior que quatro, sendo portanto considerada eficiente (EUA, 1991).

O teste de potência empregado neste experimento mostrou-se prático e de fácil execução. A utilização de bacterina monovalente de referência como alternativa para o controle das respostas induzidas

Tabela 1 - Comparativo de resultados obtidos nas titulações da suspensão de esporos realizadas no intervalo de 12 meses.

\begin{tabular}{lcc}
\hline Repetições & $1^{\text {a }}$ titulação & $2^{\text {a }}$ titulação \\
\hline Média & $1,14 \times 10^{5} \mathrm{DL}_{50} / \mathrm{mL}$ & $1,13 \times 10^{5} \mathrm{DL}_{50} / \mathrm{mL}$ \\
Desvio padrão & 0,075 & 0,075 \\
$\mathrm{CV}$ & $1,4 \%$ & $1,4 \%$ \\
\hline
\end{tabular}


Tabela 2- Resultado do teste de potência de vacinas polivalentes produzidas e comercializadas no Brasil, que continham em sua composição Clostridium sordellii.

\begin{tabular}{lcc}
\hline VACINA & TESTE* & REPETIÇÃO \\
\hline $\mathrm{T}_{1}$ & $0 / 8$ & \\
$\mathrm{~T}_{2}$ & $0 / 8$ & \\
$\mathrm{~T}_{3}$ & $0 / 8$ & \\
$\mathrm{~T}_{4}$ & $0 / 8$ & \\
$\mathrm{~T}_{5}$ & $0 / 8$ & \\
$\mathrm{~T}_{6}$ & $8 / 8$ & $6 / 8$ \\
$\mathrm{~T}_{7}$ & $0 / 8$ \\
$\mathrm{~T}_{8}$ & $8 / 8$ \\
$\mathrm{~T}_{9}$ & $0 / 8$ & \\
$\mathrm{~T}_{10}$ & $6 / 8$ & \\
$\mathrm{~T}_{11}$ & $0 / 8$ \\
$\mathrm{~T}_{12}$ & $0 / 8$ \\
bacterina referência & $8 / 8$ \\
testemunhas & $0 / 5$ & \\
\hline
\end{tabular}

*cobaias protegidas/cobaias inoculadas

pelas vacinas comerciais foi importante para confirmar as doses testes empregadas, demonstrando ser uma medida recomendada quando não se conhece o perfil de qualidade dos imunógenos que estão sendo testados.

Os resultados encontrados neste experimento, nos quais apenas três das 12 vacinas comercializadas no país mostraram-se eficientes, demonstram a baixa imunogenicidade desses imunobiológicos. Resultados semelhantes aos deste trabalho foram obtidos por outros pesquisadores ao testarem vacinas clostridiais comercializadas no país. LOBATO (1989), ao avaliar as vacinas antibotulínicas, constatou que nenhum dos produtos testados foi eficiente para estimular resposta imunológica adequada nos animais vacinados; AZEVEDO et al. (1998), ao avaliarem a eficiência de toxóides contra $\boldsymbol{C}$. perfringens tipo $\mathbf{C}$ e $\mathbf{D}$, constataram que nenhum dos produtos testados foi capaz de induzir níveis mínimos de anticorpos neutralizantes. LOBATO et al. (2000), ao avaliarem seis toxóides contra $\boldsymbol{C}$. perfringens tipo $\mathbf{C}$ e D, verificaram que somente dois foram capazes de induzir níveis de anticorpos compatíveis com os exigidos no teste de potência.

As vacinas polivalentes contra clostridioses produzidas no Brasil contêm de cinco a 11 antígenos, sendo que apenas $\boldsymbol{C}$. chauvoei e o toxóide botulínico são testados oficialmente quanto à esterilidade, inocuidade e potência pelo Ministério da Agricultura, Pecuária e Abastecimento (MAPA), ficando os demais antígenos a critério dos laboratórios produtores.
Apesar da inexistência no Brasil de diagnóstico confirmatório da ocorrência de enfermidades em animais pelo $\boldsymbol{C}$. sordellii, as vacinas contra clostridioses com múltiplos antígenos vêm sendo produzidas em larga escala, entretanto para o uso destas, deve-se considerar a prevalência da doença, o custo-benefício, bem como a comprovação de sua eficiência, premissas não consideradas na elaboração destes produtos no país; sendo portanto necessário um diagnóstico real da situação dessas enfermidades aliado à implementação de um controle pelo MAPA dos antígenos não avaliados oficialmente.

\section{CONCLUSÃO}

As vacinas contra clostridioses comercializadas no Brasil que contêm em sua composição $\boldsymbol{C}$. sordellii mostraram-se, em sua maioria, ineficientes em induzir proteção aos animais vacinados.

\section{AGRADECIMENTOS}

Os autores agradecem à "Pro-Reitoria de Pesquisa da UFMG (PRPq)" pelo apoio financeiro e ao Dr. Maurício Baltazar de Carvalho Filho (LARA-MG) pela revisão crítica deste manuscrito.

\section{REFERÊNCIASBIBLIOGRÁFICAS}

ASSIS, R.A. et al. Producción y evaluación de conjugados fluorescentes para diagnóstico de mancha y gangrena gaseosa. Rev Med Vet, (Buenos Aires), v.82, p.68-70, 2001 .

AZEVEDO, E.O. et al. Avaliação de vacinas contra Clostridium perfringens tipos C e D. Arq Bras Med Vet Zootec, v.50, n.3, p.239-242, 1998.

BIER, O. Microbiologia e imunologia. 23.ed. São Paulo: Melhoramentos, 1985. 1234p.

BUXTON, A.; FRASER, G. Animal microbiology. London: Blackwell, 1977. V.1, 358p.

EUA [Leis, etc]. Code of federal regulations. Washington: Office of the Federal Register National Archives and Records Administration, 1991. 743p.

KOLBE, D.R. et al. A method for the production of Clostridium haemolyticum spores on solid medium. J Biol Stand, v.9, n.6, p115-119, 1981.

LEWIS, C.J.; NAYLOR, R.D. Sudden death in sheep associated with Clostridium sordellii. Vet Rec, v.35, n.142, p.417-421, 1998.

LOBATO, F.C.F. Avaliação de imunógenos antibotulínicos em uso no Brasil. 1989. 59f. Dissertação (Mestrado em Medicina Veterinária Preventiva) -Escola de Veterinária da UFMG. 
LOBATO, F.C.F. et al. Avaliação da resposta de antitoxinas beta e épsilon de Clostridium perfringens induzidas em seis vacinas comerciais no Brasil. Arq Bras Med Vet Zootec, v.52, n.4, p313318,2000 .
REED, L.J.; MUENCH, H. A simple method of estimating fifty per cent endpoints. Am J Hyg, v.27, n.3, p.493-497, 1938.

RICHARDS, S.M.; HUNT, B.W. Clostridium sordellii in lambs. Vet Rec, v.111, n.1, p.22, 1982. 